\title{
A COMPARATIVE LABORATORY STUDY OF THE CLEANING EFFICIENCY OF XP ENDO FINISHER AND SONIC IRRIGATION
}

\author{
Moshira I. Hammad ${ }^{1} B D S$, Amr M. Abdallah ${ }^{2} P h D$, Nihal A. Leheta ${ }^{3} P h D$ \\ ABSTRACT
}

INTRODUCTION: Debridement of the root canal system is essential for endodontic success. Traditional instruments alone cannot sufficiently clean root canals. There must be an effective delivery system.

OBJECTIVES: was to compare the cleaning efficiency of XP-endo Finisher and the EndoActivator using the scanning electron microscope. MATERIALS AND METHODS Sixty human mandibular first premolars with single oval canals were used in this study. Teeth were instrumented using One-Shape file. Teeth were then randomly divided into three parallel groups $(n=20)$ according to the agitation method used; Group I: XP-endo Finisher. Group II: EndoActivator. Group III: both XP-endo Finisher and EndoActivator. Teeth were sectioned longitudinally and assessed by the scanning electron microscope using the five-score debris and smear layer indices. Data were analyzed using Kruskal-Wallis, Friedman, and Dunn-Bonferroni tests.

RESULTS: No significant differences were found between XP- endo Finisher and EndoActivator in debris and smear layer removal. In the middle segment, each of the XP-endo Finisher and EndoActivator revealed significantly lower debris scores than both together $(\mathrm{P}<0.05)$. In the coronal and apical segments the three groups equally cleaned debris $(\mathrm{P}>0.05)$. In smear layer removal, significant differences were found in both the coronal and apical segments between each one of the XP-endo Finisher and EndoActivator compared to both together $(\mathrm{P}<0.05)$. While in the middle segment, there were insignificant differences between the three groups in smear layer removal $(\mathrm{P}>0.05)$. The apical segment was more efficiently cleaned from debris and smear layer than the other segments in all groups.

CONCLUSIONS: Irrigation of root canals using XP-endo Finisher and EndoActivator solely was more effective in the removal of debris and smear layer than both used together. The apical third was more efficiently cleaned from debris and smear layer than the other segments. KEYWORDS: Endodontics, smear layer, debris, XP-endo Finisher, EndoActivator, scanning electron microscope.

1. Resident dentist at the Conservative Dentistry Department, Faculty of Dentistry, Alexandria University, Alexandria, Egypt.

2. Head of Conservative Dentistry Department and Professor of Endodontics, Faculty of Dentistry, Alexandria University, Alexandria, Egypt.

3. Lecturer of Endodontics, Faculty of Dentistry, Alexandria University, Alexandria, Egypt.

\section{INTRODUCTION}

Debridement of the root canal system is essential for endodontic success $(1,2)$. Shaping of root canals creates a smear layer that consists of organic and inorganic substances, including fragments of odontoblastic processes, microorganisms, and necrotic materials $(3,4)$. The smear layer has been shown to prevent the penetration of intracanal disinfectants and sealers into the dentinal tubules, which may result in compromising the seal of the root canal filling (5-8).

Complete canal debridement is difficult to achieve (8). Oval-shaped root canals are a common variation from round outlines and have a high prevalence in the apical canal portion (9). Unprepared recesses left buccally and lingually may harbor microorganisms and toxins, thus threatening the outcome of the endodontic treatment. The debris accumulation in the un-instrumented "fins" may not allow for proper disinfection and may prevent the root canal filling from reaching these recesses (10).

Therefore irrigation is an essential part of a root canal treatment as it allows for cleaning beyond the root canal instruments (11). Rinsing with sodium hypochlorite alone is unable to render the canal free of debris and smear layers (12). Even when the coronal and middle thirds of the canal are relatively clean, the apical third of the root canal always presents a problem in achieving the same level of cleanliness (13). Additionally, the packing of infected tissue into the apical extent of the canal, or out into the periapical areas, can be prevented by utilizing irrigation solutions.

The conventional endodontic irrigation syringe is the most widely used procedure (12). This is because it is very easy to manipulate and there is good control of needle depth and volume of the irrigant delivered. However, it is ineffective in the apical part of the root canal and its safety is questionable (12). This is insufficient for complete cleaning of the complex anatomy of the root canal system (14). Different irrigation techniques and devices have been developed to enhance the flow and distribution of irrigating

solutions within the root canal system reaching the apical third (12).

Therefore, a sonically-driven canal irrigation system; the EndoActivator System (EA), is designed to produce vigorous intracanal fluid agitation that has been shown to increase the efficacy of irrigation better than traditional needle irrigation (15). It comprises a portable handpiece and 3 sizes of disposable flexible polymer tips that do not cut root dentin (16).

More recently, several investigators have demonstrated that rotary systems using $\mathrm{Ni}-\mathrm{Ti}$ instruments led to good results in the instrumentation of pulp spaces (17-19). One of the recently introduced Ni-Ti files is the XP-endo Finisher file (XPF). XPF is highly flexible and shows resistance to cyclic fatigue due to its small core ISO size \# 25 and its zero degree taper (18). XPF is produced using the NiTi MaxWire alloy technology (19). It reacts at different temperature levels which improve its flexibility and provide greater resistance to cyclic fatigue (20).

The aim of the study was to compare the cleaning efficiency of XP-endo Finisher and the EndoActivator after biomechanical instrumentation. The null hypothesis was that there is no statistically significant difference between the examined agitation techniques. 


\section{MATERIALS AND METHODS}

\section{Teeth preparation}

Sixty freshly extracted human mandibular first premolar teeth with straight roots were used in this study. Prior to the experiment, teeth were stored in $10 \%$ formalin following extraction until use. Teeth were then thoroughly cleaned from any soft tissue or calculus deposition using a curette (Hu Friedy, Chicago, USA). Teeth were examined for the presence of any cracks using dental loupes (Heine, Germany) with a magnification of HR 2.5x /420 mm.

Teeth were checked by radiographs to ensure complete apex formation. All teeth were radiographed in a buccolingual and a mesio-distal direction, to ensure similar canal morphology. All apices were sealed with sticky wax to prevent the irrigation solutions from escaping through the apex to simulate in vivo situations. The crowns of all teeth were reduced using a tapered round diamond bur (MicroMega, Besancon, France) to a standardized length of 19 $\mathrm{mm}$.

Access cavities in all teeth were done. The working length (WL) was determined by subtracting $1 \mathrm{~mm}$ from the length at which an ISO \#10 K-file (Micro-Mega, Besancon, France) tip extrudes apically. Glide path was achieved using ISO \#15 K-file (Micro-Mega, Besancon, France). The canals were irrigated with saline after pulp extirpation. Teeth were prepared to K-file ISO size \#25 (Micro-Mega, Besancon, France). All sixty canals were prepared with One-Shape file (Micro-Mega, Besancon, France) to the full working length reaching a final apical preparation size of \#25/0.06. The apical diameter size reached in this study was to accommodate the apical diameter of the XP-endo Finisher file, and that of the EndoActivator's polymer tip which have apical diameters of ISO \#25/0.00 and \#25/0.04 respectively. This was not to jeopardize root strength and to preserve root dentin thickness. A contra-angle handpiece powered by an electric motor (NSK, Japan) at speed of 400 rpm and a torque level of 3 was used. All canals were prepared by the same operator in strict accordance with each manufacturer's recommendations. Irrigation with $5 \mathrm{ml}$ of $5.25 \% \mathrm{NaOCl}$ was done after each file.

\section{Final irrigation procedures}

After instrumenting the sixty canals with One-Shape file, all sixty canals were first passively filled with $5 \mathrm{ml}$ of $5.25 \%$ $\mathrm{NaOCl}$ with a flow rate of $5 \mathrm{ml} / \mathrm{min}$. A thirty-gauge irrigation needle was then placed to the deepest area apically while still kept loose in the canal, used in a pumping motion. Specimens were then randomly divided into three equal experimental groups $(n=20)$. In group I, XPendo Finisher file (FKG, Dentaire SA, La Chaux-de-Fonds, Switzerland) was set at $800 \mathrm{rpm}$ and advanced to the WL. Slow and gentle seven to eight millimeters lengthwise movements were performed for one minute. In group II, the EndoActivator System (Dentsply, Maillefer, Switzerland) was used. It was activated once at 10,000 cycles per minute using its red tip (25/0.04). In group III, Both XP-endo Finisher file and EndoActivator system were used together. The EndoActivator was used first followed by the XP- endo Finisher with the previously mentioned protocol.

\section{Scanning electron microscopic analysis}

Each specimen was then grooved vertically with a diamond disk (Brassler, USA) on its mesial and distal surfaces to weaken the root at these areas and to direct the path of fracture line. Roots were then split longitudinally with a chisel and mallet (Dentalis, USA), taking care not to contaminate the canals with cutting debris. This was done by placing a master Gutta Percha cone (Micro-Mega, Besancon, France) snugly fitting in the canal spaces. The half with the most visible part of the apex was dehydrated with ascending concentrations of ethyl alcohol (30-100 \%), and placed in a desiccator for twenty four hours. The split specimens were placed on a clean glass slab and left to further dry at room temperature for thirty minutes. The specimens were then gold plated using a fine coat of ion sputter and photographed under the SEM (JEOL, JSM 5300, Tokyo/ JAPAN).

The central beam of the SEM was directed onto the center of the canal. The photomicrographs from the apical to coronal thirds of the root of each specimen were taken at $5000 \times$ for both debris and smear layer evaluation. Photomicrographs were captured on the computer screen for scoring. Dentinal wall of each tooth was observed in the region of coronal, middle and apical thirds.

The scanning electron microscopic images were evaluated for debris and smear layer distribution. This was done using a five(21).

grade scoring system as described by Hulsmann et al

The presence of debris was evaluated by the following scores; score

1: Clean root canal wall, only few small debris particles. Score

2: Few small agglomerations of debris. Score 3: Many agglomerations of debris covering less than $50 \%$ of the root canal wall. Score 4: More than $50 \%$ of the root canal wall covered by debris. Score 5: Complete or nearly complete root canal wall covered by debris.

The presence of smear layer was also evaluated by a five-grade scoring system as follows; score 1: No smear layer, dentinal tubules open. Score 2: Small amount of smear layer, some dentinal tubules open. Score 3: Homogenous smear layer covering the root canal wall, only few dentinal tubules open. Score 4: Complete root canal wall covered by a homogenous smear layer, no open dentinal tubules. Score 5: Heavy, non-homogenous smear layer covering the complete root canal wall. The results were tabulated and submitted to statistical analysis. Representative photomicrographs of debris and smear layer of each group at the coronal, middle, and apical segments are shown in (Figure 1).

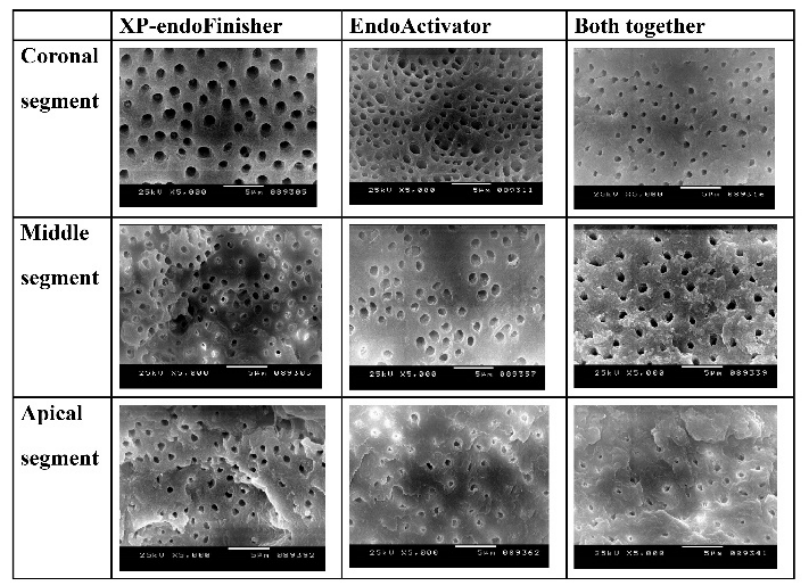

Figure 1: Showing photomicrographs of debris and smear layer of the tested groups in root canal segments. 


\section{Statistical analysis}

Data were collected and entered to the computer using Statistical Package for Social Science program, version 21 (SPSS Chicago, IL, USA). Data were entered as numerical values. When Kolmogorov-Smirnov test revealed significance, the non-parametric statistics was carried out. Comparisons were carried out among studied independent not-normally distributed subgroups using Kruskal-Wallis (KW) test. Comparisons were carried out among studied dependent not-normally distributed subgroups using Friedman test. When KW was significant, Post-hoc pairwise comparisons were carried out using Dunn-Bonferroni test. Statistical significance level was set at $\mathrm{P}<0.05$.

\section{RESULTS}

The results of debris and smear layer scores of the tested groups are presented in (Table 1).

No significant differences were found between XPendo Finisher and EndoActivator in debris and smear layer removal. In the middle segment, each of the XP-endo Finisher and EndoActivator revealed significantly lower debris scores than both together $(\mathrm{P}<0.05)$. In the coronal and apical segments the three groups equally cleaned debris ( $\mathrm{P}$ $>0.05$ ) (Figure 2). In smear layer removal, significant differences were found in both the coronal and apical segments between each one of the XP-endo Finisher and EndoActivator compared to both together $(\mathrm{P}<0.05)$. While in the middle segment, there were insignificant differences between the three groups in smear layer removal $(\mathrm{P}>0.05)$ (Figure 3). The apical segment was more efficiently cleaned from debris and smear layer than the other segments in all groups.

Table (1): Showing debris and smear layer scores in each canal segment among the studied groups.

\begin{tabular}{|c|c|c|c|c|}
\hline $\mathrm{n}=20$ & & Coronal segment & Middle segment & $\Lambda$ pical segment \\
\hline \multicolumn{5}{|l|}{ Debris scores } \\
\hline $\mathrm{XP}$-endo Finisher & $\begin{array}{l}\text { Median } \\
\text { IQR }\end{array}$ & $\begin{array}{c}1.50 \\
1.00-2.00\end{array}$ & $\begin{array}{c}1.50 \\
1.00-2.00\end{array}$ & $\begin{array}{c}1.50 \\
1.00-2.75\end{array}$ \\
\hline EndoActivator & $\begin{array}{l}\text { Mcdian } \\
\text { IQR }\end{array}$ & $\begin{array}{c}2.00 \\
1.25-2.00\end{array}$ & $\begin{array}{c}2.00 \\
1.00-2.00\end{array}$ & $\begin{array}{c}1.00 \\
1.00-1.75\end{array}$ \\
\hline \multirow[t]{2}{*}{$\begin{array}{l}\text { XP -endo Finisher } \\
\text { and EndoActivator }\end{array}$} & $\begin{array}{l}\text { Median } \\
\text { IQR }\end{array}$ & $\begin{array}{c}2.00 \\
1.00-3.00\end{array}$ & $\begin{array}{c}3.00 \\
2.00-3.00\end{array}$ & $\begin{array}{c}1.00 \\
1.002 .00\end{array}$ \\
\hline & Kruskal-Wallis test & $\begin{array}{c}\mathrm{X} 2(\mathrm{~d} I-2)-10.293 \\
\mathrm{p}(\mathrm{MC})=0.006^{*} \\
\mathrm{~N} \Lambda\end{array}$ & $\begin{array}{c}\mathrm{X} 2(\mathrm{dl}-2)-22.646 \\
{ }^{*} \mathrm{p}(\mathrm{MC})=0.006\end{array}$ & $\begin{array}{l}X 2(\mathrm{dl}-2)-4.459 \\
\mathrm{p}(\mathrm{MC})=0.108 \mathrm{NS}\end{array}$ \\
\hline \multicolumn{5}{|l|}{ Smear layer scores } \\
\hline XP - endo Finisher & $\begin{array}{l}\text { Median } \\
\text { IQR }\end{array}$ & $\begin{array}{c}2.00 \\
1.25-2.00\end{array}$ & $\begin{array}{c}2.00 \\
2.00-3.00\end{array}$ & $\begin{array}{c}2.00 \\
1.00-2.00\end{array}$ \\
\hline EndoActivator & $\begin{array}{l}\text { Median } \\
\text { IQR }\end{array}$ & $\begin{array}{c}2.00 \\
2.00-2.00\end{array}$ & $\begin{array}{c}2.00 \\
1.00-3.00\end{array}$ & $\begin{array}{c}2.00 \\
2.00-2.00\end{array}$ \\
\hline \multirow[t]{2}{*}{$\begin{array}{l}\mathrm{XP} \text {-endo Finisher } \\
\text { and FndoActivator }\end{array}$} & $\begin{array}{l}\text { Median } \\
\text { IQR }\end{array}$ & $\begin{array}{c}3.00 \\
3.00-4.00\end{array}$ & $\begin{array}{c}3.00 \\
2.00-3.00\end{array}$ & $\begin{array}{c}2.00 \\
2.00-3.00\end{array}$ \\
\hline & Kruskal-Wallis test & $\begin{array}{c}\mathrm{X} 2(\mathrm{~d}=2)=34.529 \\
{ }^{\mathrm{p}}(\mathrm{MC})=0.000\end{array}$ & $\begin{array}{l}\mathrm{X} 2(\mathrm{df}=2)=4.403 \\
\mathrm{p}(\mathrm{MC})=0.111 \mathrm{NS}\end{array}$ & $\begin{array}{l}\mathrm{X} 2(\mathrm{df}=2)=7.339 \\
{ }^{*} \mathrm{p}(\mathrm{MC})=0.025\end{array}$ \\
\hline
\end{tabular}
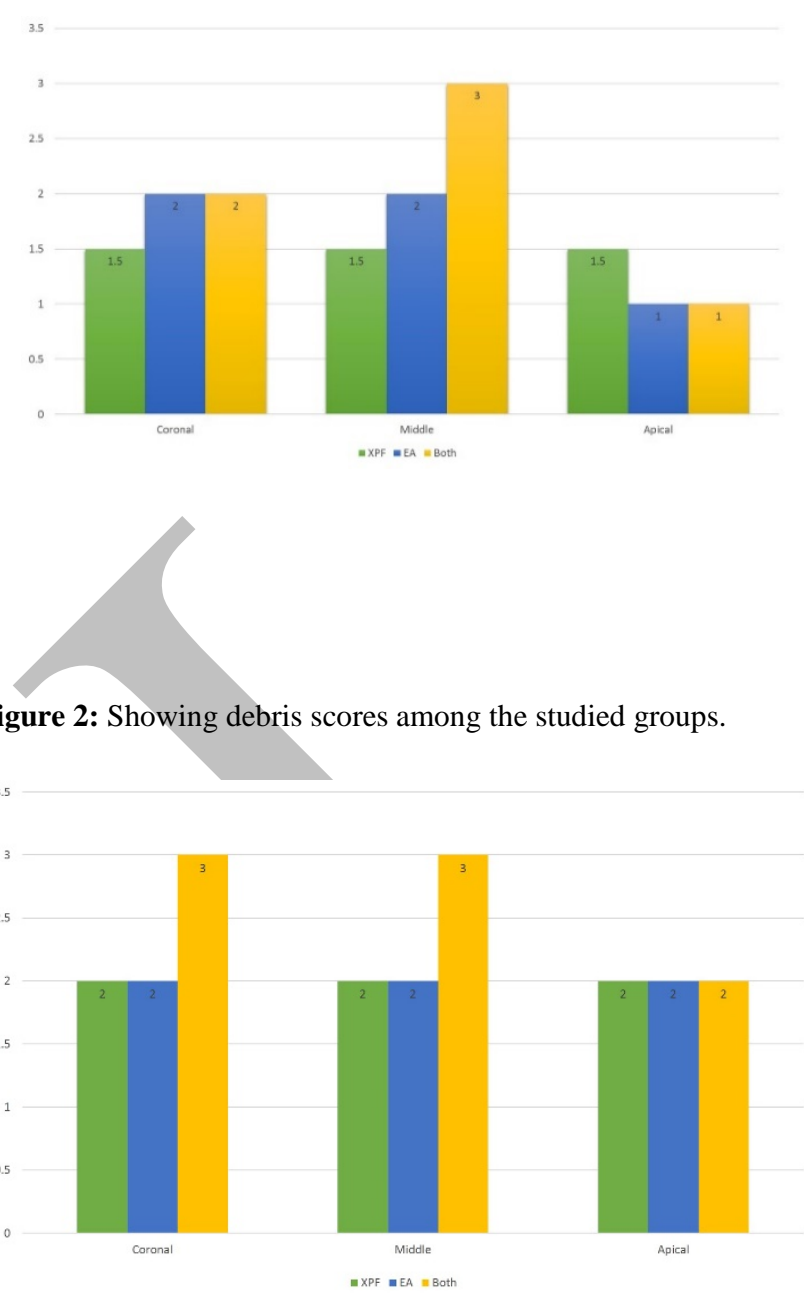

Figure 3: Showing smear layer scores among the studied groups.

\section{DISCUSSION:}

Removal of all microorganisms, microbial by-products, vital and necrotic tissue is the goal of endodontic therapy (22). This is accomplished during the chemo-mechanical preparation of the canal space. However, due to the intricate nature and inherent complexities associated with canal anatomy, this goal is never completely achieved. Multiple studies have suggested that bacteria and debris remain within the root canal system even after meticulous chemomechanical debridement (23-26). Sufficient disinfection of these root canal complexities cannot be accomplished with traditional instruments alone (22). However, some studies have suggested that the activation of the irrigation solutions can increase the efficacy of debris and smear layer removal in all areas of the canal system $(22,23,26)$.

SEM is the most widely used method for the assessment of the cleaning efficiency of irrigation. This is for several reasons. First, it is a valuable tool to assess the cleanliness of canal walls (24). Second, it has a large depth of field which allows more of the specimens to be in focus one at a time simultaneously in high resolution (25). Third, it aids in the examination of dentinal tubules with respect to the presence of the smear layer (25). Fourth, it helps in the assessment of the whole segment of the canal on the basis of a distinct numeric evaluation score for debris and smear layer $(16,22)$. The results lead to the rejection of the null hypothesis since differences in debris and smear layer removal were found between the groups. 
In this study, sodium hypochlorite $(\mathrm{NaOCl})$ was used as an irrigating solution since it is the most popular irrigant used (26). It is the only irrigant capable of dissolving organic tissues such as; pulpal tissue, necrotic tissues, biofilm and organic part of smear layer (27). NaOCl exhibits potent and rapid antibacterial effect in vitro (26). It also acts as a lubricant which facilitates the passage of files in the root canals (28).

Ethylenediaminetetraacetic acid (EDTA) was not used in this study. This was because EDTA could have had an effect on smear layer removal masking the actual action of XP-endo Finisher and EndoActivator independently.

When both the XP- endo Finisher and the EndoActivator were used together, the debris scores were significantly higher than when the two were used solely in the coronal and middle segments. However, in the apical segment there were no significant differences in debris removal between the three groups. Moreover, both together revealed significantly higher smear layer scores in the coronal and apical segments than each used solely. Conversely, in the middle segment there were no significant differences in smear layer removal between the three groups.

The findings in this study regarding the debris and smear layer removal can be attributed to the XP-endo Finisher's expansion capacity and shape memory of the NiTi alloy. These characteristics permit the file to contact and clean areas that are otherwise difficult to reach with regular instruments, especially the apical segment (18). The file is straight in its Martensitic phase (M-phase), which is achieved when it is cooled (29). When the file is exposed to the body temperature; inside the canal, it will change its shape due to its molecular memory to the spoon-shaped Austenitic phase (A-phase). The A-phase shape in the rotation mode allows the file to access and clean areas that are otherwise impossible to reach with standard instruments (28).

The cleaning efficiency of the EndoActivator can be explained by its hydrodynamic phenomenon that promotes deep cleaning and disinfection. It has been shown that cavitation and acoustic streaming significantly improve debridement and the disruption of the smear layer and biofilm (16).

Analysis of each root canal segment within the same group after final irrigation showed that the apical segment was the most efficiently cleaned segment from debris and smear layer. This is what all previous studies were striving to achieve.

It has been reported that root canals could efficiently be prepared up to size \# 20/0.06 using rotary files (30). In this study, the last file used to prepare root canals was K-file size \# 25/0.02, followed by One-Shape file size \#25/0.06. This was not to jeopardize root strength and to preserve root dentin thickness.

In this study, all files were only used once before being discarded as this may affect the cutting and cleaning efficiency of each file used affecting the amount of touched dentin (31).

The scoring method used in this study involved qualitative analysis which is a simple and direct scoring system. Moreover, the large number of observations made increased the reliability of the obtained results (19).

\section{CONCLUSION}

In this study, it can be concluded that irrigation of root canals using XP-endo Finisher and EndoActivator methods solely seems to be more effective in the removal of debris and smear layer than both instruments used together. None of the irrigation methods assessed in this study totally removed the debris and smear layer. It was also concluded that the apical third was more efficiently cleaned from debris and smear layer than the other segments in the studied groups.

\section{Acknowledgements}

The authors would like to thank Prof. Raef A.Sherif for providing the EndoActivator used in this study.

\section{Conflict of interest}

The authors declare that they have no conflicts of interest.

\section{REFERENCES}

1- Örstavik D, Ford T. Essential Endodontology: Prevention and Treatment of Apical Periodontitis, 2nd ed. NJ: Blackwell W Ltd; 2008:6-20.

2- Shilder H. Cleaning and Shaping the Root Canal. Dent Clin North Am. 1974; 18: 269-96.

3- Heard F, Walton R. Scanning Electron Microscope Study Comparing Four Root Canal Preparation Techniques in Small Curved Canals. Int Endod J. 1997; 30: 323-31.

4- Peters C, Barbakow F. Effect of Irrigation on Debris and Smear Layer on Canal Walls Prepared by Two Rotary Techniques: A Scanning Electron Microscopic Study. J Endod. 2000; 25: 6-10.

5- Örstavik D, Haapasalo M. Disinfection by Endodontic Irrigants and Dressings of Experimentally Infected Dentinal Tubules. Endod Dent Traumatol. 1990; 6: 142-9.

6- White R, Goldman M, Lin P. The Influence of the Smeared Layer upon Dentinal Tubule Penetration by Endodontic Filling Materials (part II). J Endod. 1987; 13: 369-74.

7- Kennedy W, Walker W, Gough R. Smear Layer Removal Effects on Apical Leakage. J Endod. 1986; 12: 21-7.

8- Saunders W, Saunders E. The Effect of Smear Layer upon the Coronal Leakage of Gutta-Percha Fillings and a Glass Ionomer Sealer. Int Endod J. 1992; 25: 245-9.

9- Hartmann M, Barletta F, Fontanella V, Vanni J. Canal Transportation after Root Canal Instrumentation: A Comparative Study with Computed Tomography. J Endod. 2007;33:962-5.

10- Iqbal M, Maggiore F, Suh B Edwards K, Kang J, Kim S. Comparison of Apical Transportation in Four Ni-Ti Rotary Instrumentation Techniques. J Endod. 2003;29:587-91.

11- Johnson E, Lloyd A, Kuttler S, Namerow K. Comparison between a Novel Nickel-Titanium Alloy and 508 Nitinol on the Cyclic Fatigue Life of ProFile 25/.04 Rotary Instruments. J Endod. 2008;34:1406-9.

12- Nielsen B, Baumgartner C. Comparison of the EndoVac System to Needle Irrigation of Root Canals. J Endod. 2007; 33: 611-5.

13- Van der Sluis L, Versluis M, Wu M, Wesselink P. Passive Ultrasonic Irrigation of the Root Canal: A Review of the Literature. Int Endod J. 2007; 40: 415-26

14- Ram Z. Effectiveness of Root Canal Irrigation. Oral Surg Oral Med Oral Pathol. 1977;44:306-12. 
15- Uroz-Torres D, Gonzales-Rodriguez M, Ferrer-Luque C. Effectiveness of the EndoActivator System in Removing the Smear Layer after Root Canal Instrumentation. J Endod. 2010; 36:308-11.

16- Ruddle C. Endodontic Disinfection: Tsunami Irrigation. Endod Practice. 2008; 11:7-15.

17- Jensen S, Walker T, Hutter J, Nicoll B. Comparison of the Cleaning Efficacy of Passive Sonic Activation and Passive Ultrasonic Activation after Hand Instrumentation in Molar Root Canals. J Endod. 1999; 25: 735-8.

18- Hugo R, Karla C. Efficacy of Three Different Endodontic Irrigation Systems for Irrigant Delivery to Working Length of Mesial Canals of Mandibular Molars J Endod. 2012;38:445-8.

19- Kuah H, Lui J, Tseng P, Chen N. The Effect of EDTA with and without Ultrasonics on Removal of the Smear Layer. J Endod. 2009; 35: 393-6.

20- Nielsen B, Baumgartner C. Comparison of the EndoVac System to Needle Irrigation of Root Canals. J Endod. 2007; 33: 611-5.

21- Hulsman M, Rummelin C, Schafers F. Root Canal Cleanliness after Preparation with Different Endodontic Handpieces and Hand Instruments: A Comparative SEM Investigation. J Endod. 1997; 23 : 301-6.

22- Binkley S. An In- Vitro SEM Study Comparing the Debridement Efficacy of the EndoActivator System Versus the Ultrasonic Bypass System Following HandRotary Instrumentation. Master's Thesis, Indiana Univ; 2010.

23- Klyn S, Kirkpatrick T, Rutledge R. In Vitro Comparisons of Debris Removal of the EndoActivatorTM System, the F FileTM, Ultrasonic Irrigation, and $\mathrm{NaOCl}$ Irrigation Alone after Handrotary Instrumentation in Human Mandibular Molars. J Endod. 2010;36:1367-71.

24- Kamel W, Kataia E. Comparison of the Efficacy of Smear Clear with and without a Canal Brush in Smear Layer and Debris Removal from Instrumented Root Canal Using Wave One Versus ProTaper: A Scanning Electron Microscopic Study. J Endod. 2014;40:44650.

25- Yana Y. An In Vivo Comparative Study of the Penetration of Sodium Hypochlorite in Root Canal Systems During Cleaning and Shaping Procedures Using the B.U. Technique and Sonic Instrumentation. Master's Thesis, Boston Univ; 1989.

26- $\mathrm{Hu} \mathrm{X}$, Peng $\mathrm{Y}$, Sum CP, Ling J. Effects of Concentrations and Exposure Times of Sodium Hypochlorite on Dentin De-Proteination: Attenuated Total Reflection Fourier Transform Infrared Spectroscopy Study. J Endod. 2010;36:2008-11.

27- Johnson W, Noblett W. Cleaning and Shaping in: Endodontics: Principles and Practice, 4th ed. Philadelphia: Saunders; 2009: 12-50.

28- Trope M, Debelian G. XP-3D Finisher File - The Next Step in Restorative Endodontics.

Endod Practice US. 2015; 8: 14-6.

29- Živković S, Nešković J, Jovanović-Medojević M, Popović-Bajić M, Živković-Sandić M. XP-endo Finisher: A New Solution for Smear Layer Removal. Serbian Dent J. 2015;62:314-78.
30- Lertchirakarn V, Palamara J, Messer H. Patterns of Vertical Root Fracture: Factors Affecting Stress Distribution in the Root Canal. J Endod. 2003;29:523-8.

31- Keleş A, Alcin H, Kamalak A, Versiani M. Ovalshaped Canal Retreatment with Self-Adjusting File: A Micro-Computed Tomography Study. Clin Oral Investig. 2014;18:1147-53. 